\title{
Journal of Melittology
}

Bee Biology, Ecology, Evolution, \& Systematics

The latest buzz in bee biology

No. 76, pp. 1-6

13 April 2018

\section{BRIEF COMMUNICATION}

\section{A record of bilateral gynandromorphism in Epeolus (Hymenoptera: Apidae: Nomadinae)}

\author{
Thomas M. Onuferko ${ }^{1}$
}

\begin{abstract}
The discovery of a gynandromorph of a North American Epeolus Latreille is reported. A specimen of Epeolus flavofasciatus Smith from Flagstaff, Arizona, USA discovered in the collection of the American Museum of Natural History (AMNH) exhibits male-specific features on the left and female-specific features on the right, consistent with bilateral gynandromorphism (the first known case in the genus). Descriptions and images of the aberrant features exhibited by the specimen are presented.
\end{abstract}

Gynandromorphism is a rare condition in which an individual exhibits both female and male features. Among bees, numerous examples have been documented and occurrences reviewed several times recently (Wcislo et al., 2004; Michez et al., 2009; Hinojosa-Díaz et al., 2012; Lucia \& Gonzalez, 2013). There are three commonly accepted categories of gynandromorphs: bilateral, mosaic, and transverse, of which mosaic and transverse appear to be the most common (Michez et al., 2009; Hinojosa-Díaz et al., 2012). Although this condition has been documented in a wide range of long-tongued bees (Apidae and Megachilidae), there are few known examples of cleptoparasitic apid gynandromorphs. At least three instances (one mosaic, two transverse) in Nomada Scopoli (Nomadinae: Nomadini) have been documented (Schenk, 1871; Tsuneki, 1975; Pérez-Iñigo Mora, 1982, respectively). Engel (2007) described and figured a bilateral gynandromorph in the melectine genus Thyreus Panzer, and Wolf (2000) documented a transverse gynander of Epeolus julliani Pérez (Nomadinae: Epeolini). To my knowledge, however, bilateral gynandromorphism in Epeolus Latreille has never before been reported, and no gynander in the genus has been described, dissected, or imaged.

Among the specimens borrowed and studied from the American Museum of Natural History (AMNH) for the purpose of revising all Nearctic Epeolus (Onuferko, in

\footnotetext{
${ }^{1}$ Department of Biology, York University, 4700 Keele St., Toronto, Ontario M3J 1P3, Canada (thomas.onuferko@gmail.com).

doi: http://dx.doi.org/10.17161/jom.v0i76.7056
}

Copyright $(\odot)$ T.M. Onuferko.

Creative Commons Attribution-NonCommercial-NoDerivatives 4.0 International (CC BY-NC-ND 4.0).

ISSN 2325-4467 

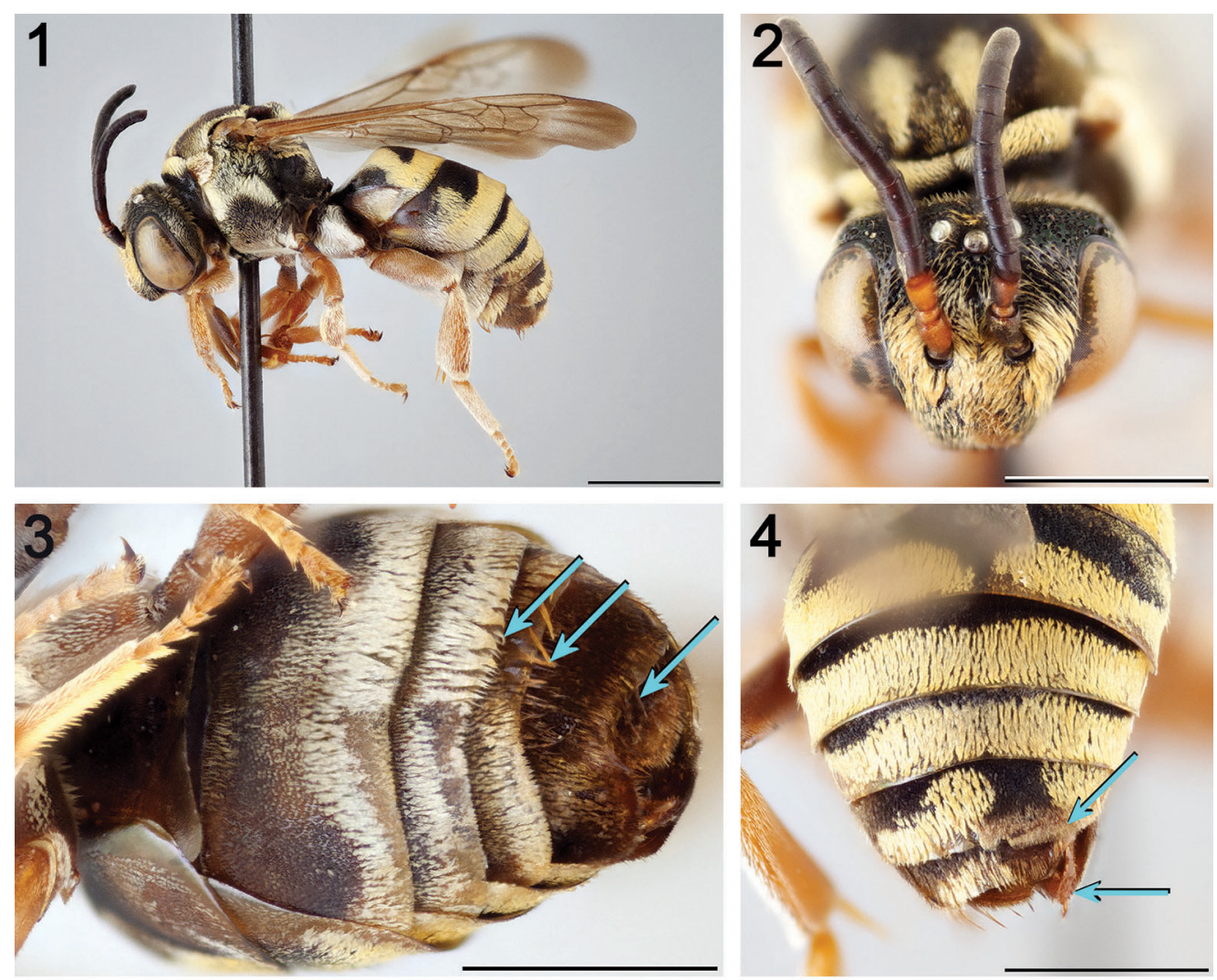

Figures 1-4. Epeolus flavofasciatus Smith gynander (prior to dissection). 1. Lateral habitus (scale bar $=3 \mathrm{~mm}$ ). 2. Head (in frontal view) showing the antenna with 10 flagellomeres on the specimen's right side and 11 on the specimen's left side (scale bar $=2 \mathrm{~mm}$ ). 3. Metasomal sterna (in ventral view) with the arrows showing S3-S5 with long curved coppery to silvery subapical hairs, which are characteristic of male Epeolus, on the specimen's left side (scale bar $=2 \mathrm{~mm}$ ). 4 . Metasomal terga (in dorsal view) showing the pseudopygidial area (diagonal arrow), which is present only in females, and a single lateral apical process of the female S6 (horizontal arrow) (scale bar $=2 \mathrm{~mm}$ ).

press) was a specimen of E. flavofasciatus Smith exhibiting male-specific features on the left side and female-specific features on the right side. The specimen was collected in Flagstaff (Coconino County), Arizona, USA on 25.vii.1952 [25 July 1952] by M. Cazier, W. Gertsch, and R. Schrammel. As part of my revision, I have examined the primary type specimens of all species of Epeolus known to occur north of Mexico, including two syntypes (a female [catalog number: 010812212] and male [catalog number: 010812250]) of E. flavofasciatus (housed at the Natural History Museum in London, United Kingdom [NHMUK]) and the male holotype (catalog number: 534034) of Triepeolus (now Epeolus) agaricifer Cockerell (housed at the U.S. National Entomological Collection, National Museum of Natural History, Washington, D.C., USA [USNM]), which Rightmyer (2008) synonymized under E. flavofasciatus. The species is little known but diagnosable according to the following morphological features, which are visible in the gynander: the mesoscutum has two short longitudinal lines of pale yellow tomentum (paramedian bands [Rightmyer, 2008; Onuferko, 2017]), the metanotum is flat, the first metasomal tergum (T1) has a patch of black pubescence (discal 

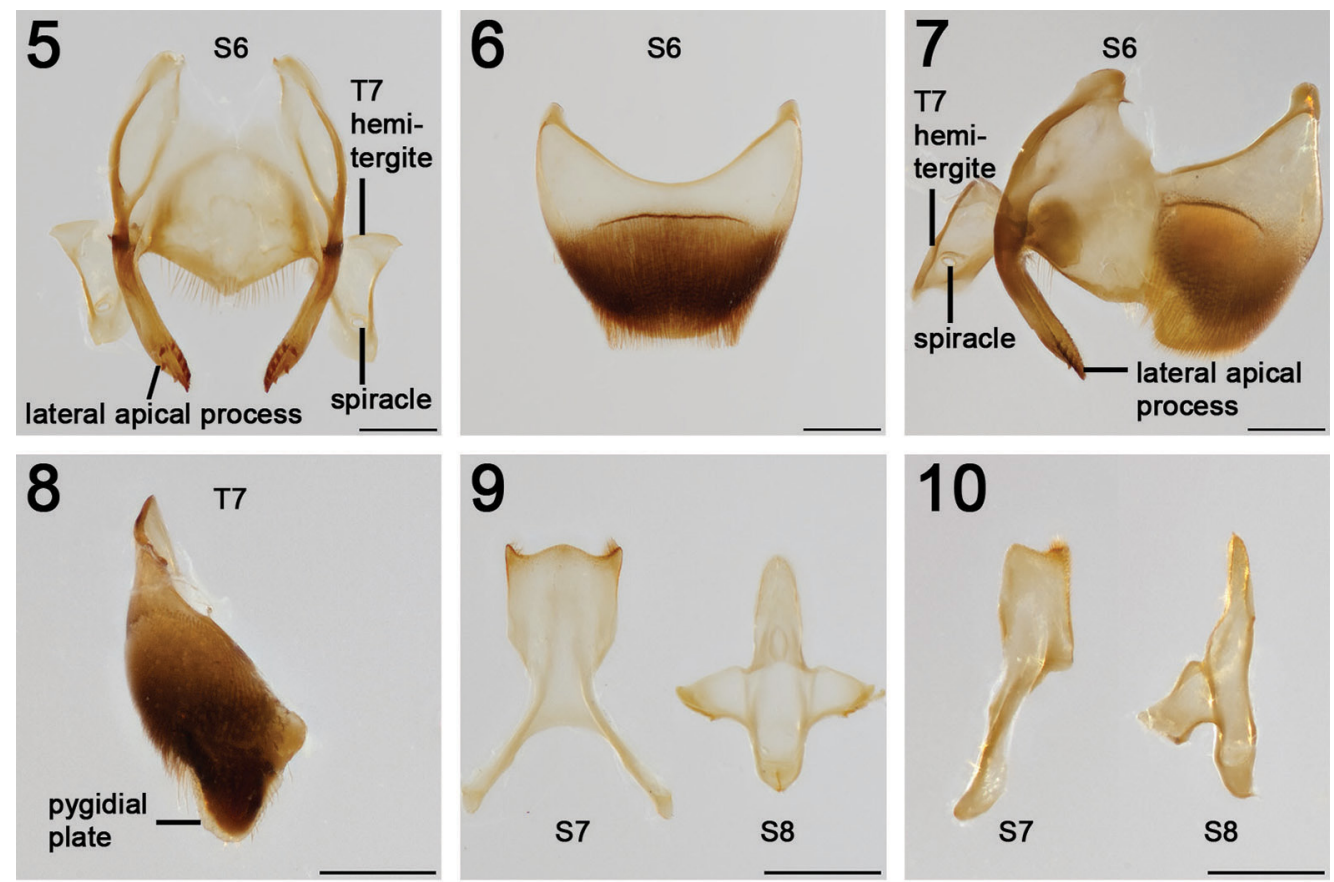

Figures 5-10. Epeolus flavofasciatus Smith apical segments of a female, male, and the newly discovered gynander (removed and cleared in $\mathrm{KOH}$ ). 5. Female S6 with T7 hemitergites attached. 6. Male S6. 7. S6 of the gynander (with $q$ and $\delta$ portions fused). 8. T7 of the gynander ( $\delta$ portion in dorsal view). 9. Male S7 and S8. 10. S7 and S8 of the gynander ( $\delta$ portion). Scale bars $=0.5 \mathrm{~mm}$.

patch [Rightmyer, 2008; Onuferko, 2017]) in the shape of an agaric, and the metasomal fasciae are yellowish.

Prior to dissection, the specimen was placed in a relaxation chamber (a sealed plastic container containing water-soaked tissue paper) for about 20 hours. The terminalia were excised using an insect pin (size 0 ) to punch holes and rip through the conjunctival membrane separating the fifth and sixth metasomal terga and sterna ( $\mathrm{T}$ and $\mathrm{S}$, respectively). The terminalia, T6, and S6 were then placed in a solution containing potassium hydroxide and water (prepared by dropping a pellet of $\mathrm{KOH}$ into about $1 \mathrm{~mL} \mathrm{H}_{2} \mathrm{O}$ ) for approximately four hours before being transferred to glycerin. The specimen was photographed with a digital camera (Canon EOS 40D SLR) using the Visionary Digital macro-imaging BK PLUS Lab System. The images were then focus stacked in Helicon Focus and edited in Adobe Photoshop and PaintShop Pro. Finally, the terminalia, T6, and S6 were transferred to a glass vial containing a small amount of glycerin for indefinite storage. The vial's rubber cap is pinned under the specimen. For comparison, conspecifics (a female and male) were also dissected following the same procedure.

Detailed examination of the studied specimen (Figs. 1-4) revealed the following male-specific features left of the midline: the antenna has 11 flagellomeres (Fig. 2); the third, fourth, and fifth metasomal sterna (S3-S5) have long curved coppery to silvery subapical hairs (Fig. 3) (these are present on S4 and S5 of males of most species of Epeolus [S3-S5 in male E. flavofasciatus] whereas in females any subapical hairs are very short and straight); T5 and T6 have apical fasciae (Fig. 4); and S6 is extended. Prior to dissection, the following female-specific features were observed right of the midline: 

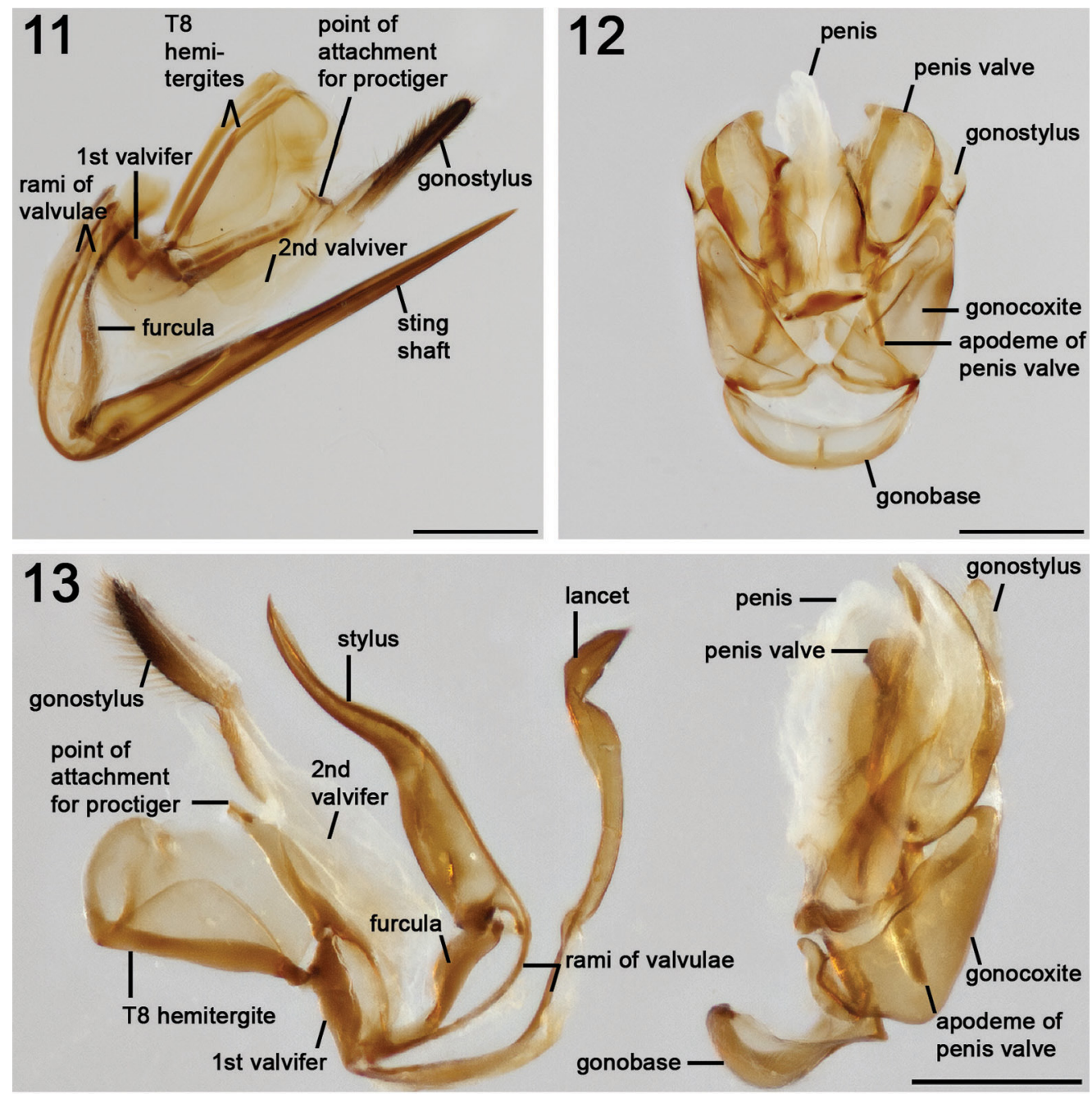

Figures 11-13. Epeolus flavofasciatus Smith terminalia of a female, male, and the newly discovered gynander (removed and cleared in $\mathrm{KOH}$ ). 11. Female sting apparatus (in lateral view). 12. Male genitalia (in dorsal view). 13. Genitalia of the gynander (with $q$ portion on the left [specimen's right] side and $\delta$ portion on the right [specimen's left]) side. Scale bars $=0.5 \mathrm{~mm}$.

the antenna has 10 flagellomeres (Fig. 2); S3-S5 have comparatively short subapical hairs, which are straight and extend very little or do not extend beyond the apex of the sternum (Fig. 3); T5 has a lunate pseudopygidial area and large patch of yellow tomentum to its right (a second patch [two separate patches are characteristic of females] is also partially present on the left but this joins the apical fascia of the male portion) (Fig. 4); T6 has most of the female pygidial plate, which is skewed to the right.

Dissection revealed additional abnormalities. In Epeolus, the female S6 is distinctive and the presence of a pair of convergent lateral apical processes covered in setae modified into pointed denticles (Fig. 5) is diagnostic for the genus; females presumably use them to cut through the polyester-like lining separating the brood cells or covering the cell walls inside the nests of their hosts (Colletes Latreille spp.) (Torchio \& Burdick, 1988). Unlike the male S6 (Fig. 6), the female S6 is internal. In the gynander, 
the female and male portions of the S6 are more or less separated by the midline (Fig. 7). A single lateral apical process is visible, and a female T7 hemitergite is attached to the female portion of the S6. Prior to dissection, the female portion was mostly internal whereas the male portion was extended. The male T7 is present in part and has the male pygidial plate (Fig. 8), but unusually it was completely internal. The male S7 was recovered, which instead of the usual pair of processes present in male Epeolus (Fig. 9) has a single distal process (Fig. 10), as was the male S8, which instead of the usual pair of apodemes (Fig. 9) has a single mediolateral apodeme (Fig. 10). Although malformed, many of the anatomical features of the female sting apparatus (Fig. 11) and male genital capsule (Fig. 12) are clearly visible in the gynander (Fig. 13). The female sting apparatus and male genital capsule were also divided roughly into two halves, which separated from one another once the $\mathrm{KOH}$ digested the tissues.

The mesosoma does not differ between the sexes of E. flavofasciatus, but the approximate separation of female- and male-specific features on the head and metasoma by the midline is strongly indicative of bilateral gynandromorphism. Thus, this specimen appears to represent the first known case of bilateral gynandromorphism in Epeolus, the second documented instance of gynandromorphism in the genus, the fifth known gynander in Nomadinae, and one of less than 200 species of bees (Hymenoptera: Apoidea) in which instances of gynandromorphism have been documented.

\section{ACKNOWLEDGEMENTS}

I thank Jerome G. Rozen (AMNH) for permission to borrow and dissect the Epeolus gynander and a conspecific female for study and imaging, and Laurence Packer for providing me with the male specimen and constructive feedback on the note. I am grateful to David Notton (NHMUK) and both Seán Brady and Brian Harris (USNM) for making available the primary types of E. flavofasciatus and T. agaricifer, respectively, to me for study. The imaging system I used was purchased through Canadensys with funds from the Canadian Foundation for Innovation and the Ontario Research Fund. While preparing this paper I was supported financially by a Susan Mann Dissertation Scholarship (issued by the Faculty of Graduate Studies at York University), for which I am most grateful. Lastly, I thank two anonymous individuals for reviewing this brief communication for the Journal of Melittology.

\section{REFERENCES}

Engel, M.S. 2007. Lateral gynandromorph in the bee genus Thyreus and the sting mechanism in the Melectini (Hymenoptera: Apidae). American Museum Novitates 3553: 1-11.

Hinojosa-Díaz, I.A., V.H. Gonzalez, R. Ayala, J. Mérida, P. Sagot, \& M.S. Engel. 2012. New orchid and leaf-cutter bee gynandromorphs, with an updated review (Hymenoptera, Apoidea). Zoosystematics and Evolution 88(2): 205-214.

Lucia, M., \& V.H. Gonzalez. 2013. A new gynandromorph of Xylocopa frontalis with a review of gynandromorphism in Xylocopa (Hymenoptera: Apidae: Xylocopini). Annals of the Entomological Society of America 106(6): 853-856.

Michez, D., P. Rasmont, M. Terzo, \& N.J. Vereecken. 2009. A synthesis of gynandromorphy among wild bees (Hymenoptera: Apoidea), with an annotated description of several new cases. Annales de la Société Entomologique de France 45(3): 365-375.

Onuferko, T.M. 2017. Cleptoparasitic bees of the genus Epeolus Latreille (Hymenoptera: Apidae) in Canada. Canadian Journal of Arthropod Identification 30: 1-62.

Onuferko, T.M. In press. A revision of the cleptoparasitic bee genus Epeolus Latreille for Nearctic species, north of Mexico (Hymenoptera, Apidae). ZooKeys

Pérez-Iñigo Mora, C. 1982. Sobre dos interesantes casos teratológicos en Apoideos (Hym. Apoidea). Boletín de la Asociación Española de Entomología 6(1): 29-31. 
Rightmyer, M.G. 2008. A review of the cleptoparasitic bee genus Triepeolus (Hymenoptera: Apidae). Part I. Zootaxa 1710: 1-170.

Schenk, U. 1871. Einige Bienen-Hermaphroditen. Entomologische Zeitung 32(10-12): 335.

Torchio, P.F., \& D.J. Burdick. 1988. Comparative notes on the biology and development of Epeolus compactus Cresson, a cleptoparasite of Colletes kincaidii Cockerell (Hymenoptera: Anthophoridae, Colletidae). Annals of the Entomological Society of America 81(4): 626-636.

Tsuneki, K. 1975. A partial gynandromorph appeared in the cuckoo bee Nomada sp. (Hymenoptera, Apidae). Kontyû 43: 173-180.

Wcislo, W.T., V.H. Gonzalez, \& L. Arneson. 2004. A review of deviant phenotypes in bees in relation to brood parasitism, and a gynandromorph of Megalopta genalis (Hymenoptera: Halictidae). Journal of Natural History 38(11): 1443-1457.

Wolf, H. 2000. Ein Zwitter von Epeolus julliani Pérez 1884 (Hymenoptera, Apidae). Linzer biologische Beiträge 32(2): 1321-1322. 



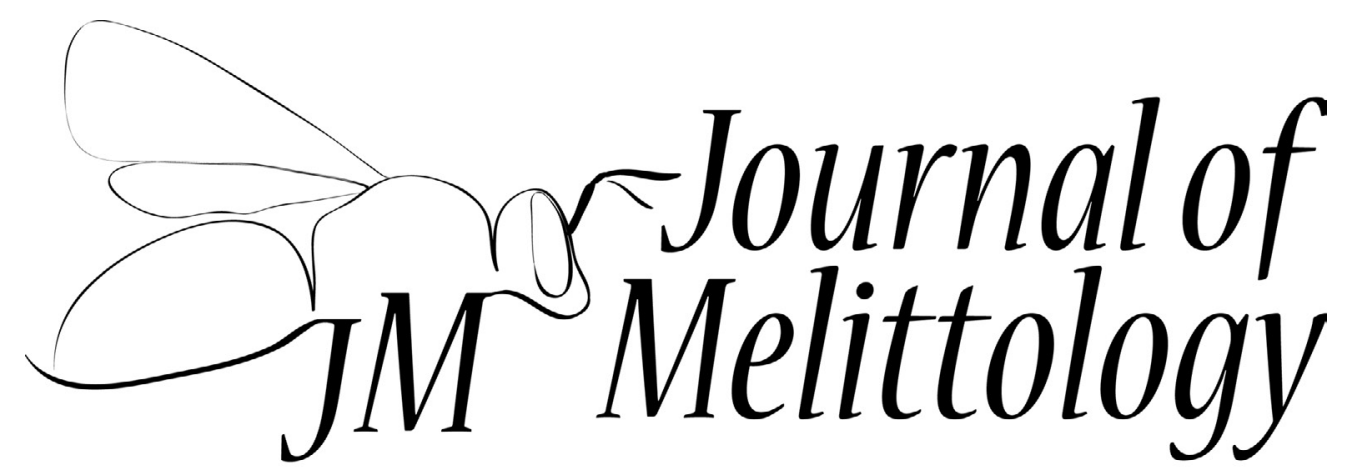

A Journal of Bee Biology, Ecology, Evolution, \& Systematics

The Journal of Melittology is an international, open access journal that seeks to rapidly disseminate the results of research conducted on bees (Apoidea: Anthophila) in their broadest sense. Our mission is to promote the understanding and conservation of wild and managed bees and to facilitate communication and collaboration among researchers and the public worldwide. The Journal covers all aspects of bee research including but not limited to: anatomy, behavioral ecology, biodiversity, biogeography, chemical ecology, comparative morphology, conservation, cultural aspects, cytogenetics, ecology, ethnobiology, history, identification (keys), invasion ecology, management, melittopalynology, molecular ecology, neurobiology, occurrence data, paleontology, parasitism, phenology, phylogeny, physiology, pollination biology, sociobiology, systematics, and taxonomy.

The Journal of Melittology was established at the University of Kansas through the efforts of Michael S. Engel, Victor H. Gonzalez, Ismael A. Hinojosa-Díaz, and Charles D. Michener in 2013 and each article is published as its own number, with issues appearing online as soon as they are ready. Papers are composed using Microsoft Word ${ }^{\circledR}$ and Adobe InDesign ${ }^{\circledR}$ in Lawrence, Kansas, USA.

\section{Editor-in-Chief \\ Michael S. Engel \\ University of Kansas}

Victor H. Gonzalez

University of Kansas

Claus Rasmussen

Aarhus University

\section{Assistant Editors}

Ismael A. Hinojosa-Díaz

Universidad Nacional Autónoma de México

Cory S. Sheffield

Royal Saskatchewan Museum

Journal of Melittology is registered in ZooBank (www.zoobank.org), and archived at the University of Kansas and in Portico (www.portico.org). 